\title{
Drying kinetics and product quality of dried chempedak.
}

\begin{abstract}
The objective of this study was to investigate the drying kinetics of chempedak (Artocarpus integer) at different drying temperatures $\left(50{ }^{\circ} \mathrm{C}, 60{ }^{\circ} \mathrm{C}, 70{ }^{\circ} \mathrm{C}\right)$ and slab dimensions. The drying data were fitted to the different semi-theoretical models based on moisture ratio (MR) to predict the drying kinetics. A logarithmic model was found to be the best fit in this study for all the drying temperatures tested. Effective diffusivities were estimated from Fick's 2nd law and the Arrhenius equation was used to determine the diffusivity constant (Do) and activation energy $(\mathrm{Ea})$. The texture and color of dried product were altered significantly during drying. The total color change $(\Delta \mathrm{E})$, hardness and chewiness were found to be increased with elevated temperature; meanwhile, springiness and cohesiveness of dried chempedak were relatively constant.
\end{abstract}

Keyword: Drying kinetics; Diffusivity constant; Activation energy; Texture; Total color change 